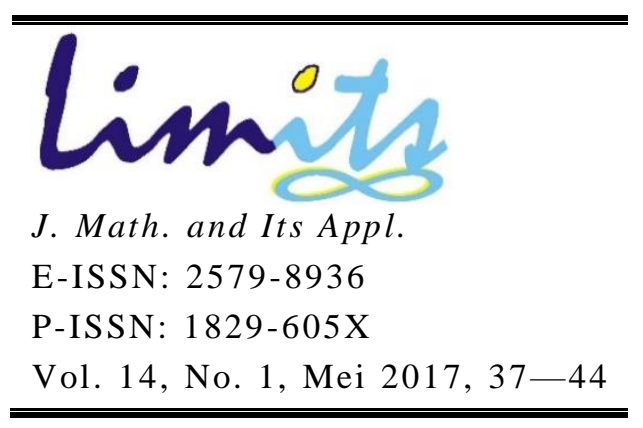

\title{
ENUMERASI GRAF SEDERHANA DENGAN ENAM SIMPUL MENGGUNAKAN TEOREMA POLYA
}

\author{
Soleha $^{1}$, I Gst Ngurah Rai Usadha ${ }^{2}$, Ahmad Jamil ${ }^{3}$ \\ ${ }^{1,2,3}$ Institut Teknologi Sepuluh Nopember (ITS) \\ ${ }^{1}$ seha_07@matematika.its.ac.id
}

\begin{abstract}
Abstrak
Salah satu dari dari masalah yang sering muncul dalam matematika adalah masalah enumerasi atau pencacahan objek dari suatu pengaturan. Seperti diketahui, dari beberapa permasalahan matematika yang rumit terkait pada masalah enumerasi tersebut. Hal ini lebih dikarenakan permasalahan konspetual yaitu ketika objek berbeda dapat dipandang sama (isomorfis). Selain grup permutasi, penyelesaian permasalahan enumerasi juga melibatkan Teorema Polya I dan Teorema Polya II. Teorema Polya I digunakan untuk menentukan banyaknya objek yang tidak isomorfis sedangkan Teorema Polya II digunakan untuk menentukan bentuk-bentuk objek yang tidak isomorfis tersebut. Beberapa tahun terakhir dilakukan penelitian terkait permasalahan enumerasi pada graf sederhana. Lebih detailnya, permasalahan mengenai banyaknya graf sederhana dengan empat (lima) simpul yang tidak isomorfis menggunakan konsep grup simetri $S_{4}\left(S_{5}\right)$, Teorema Polya I serta Teorema Polya II sehingga diperoleh hasil sebelas graf sederhana yang tidak saling isomorfis dengan empat simpul dan tiga puluh lima dengan lima simpul.. Pada Penelitian ini diselidiki banyaknya graf sederhana dengan enam simpul yang tidak isomorfis menggunakan konsep grup simetri $S_{6}$, Teorema Polya I serta Teorema Polya II sehingga diperoleh hasil seratus lima puluh enam graf sederhana yang tidak saling isomorfis.

Kata Kunci: Enumerasi, Graf Sederhana, Grup Permutasi, Isomorfis, Teorema Polya.
\end{abstract}

\section{Pendahuluan}

Ilmu matematika merupakan ilmu dasar yang dapat diaplikasikan di berbagai bidang. Kajian matematika umumnya dibedakan menjadi matematika murni dan matematika terapan. Kajian matematika murni salah satunya adalah aljabar. Aljabar dimulai dari himpunan dan operasi. Himpunan yang dilengkapi satu operasi disebut 
grup. Salah satu contoh grup adalah grup permutasi. Matematikawan Lagrange mengawali kajian permutasi dalam hubungannya dengan solusi persamaan, pada tahun 1770. Hal ini yang mendorong Galois pada abad 19 menemukan konsep grup permutasi. Grup permutasi adalah sebuah grup yang elemen-elemennya merupakan permutasi dari suatu himpunan dengan operasi komposisi. Sedangkan Cayley, pada 1854 mendefinisikan grup abstrak berhingga dan mempresentasikan beberapa contoh grup lainnya seperti grup Quatenions, grup matriks invertible, dll. Selanjutnya, Cayley menemukan bahwa setiap grup abstrak isomorfis dengan grup permutasi, suatu hasil yang sekarang dikenal sebagai "Teorema Cayley". Melanjutkan hasil dari Cayley, komunitas matematika pada tahun 1880 menunjukkan bahwa teori grup berperan besar di berbagai bidang matematika, seperti bagian lain dari aljabar, yaitu geometri, teori bilangan dan analisis [1].

Saat ini, tepatnya seratus tiga puluh empat tahun kemudian, teori grup telah banyak berperan tidak hanya di bidang matematika yaitu kriptografi, statistika, teori koding, teori graf, melainkan juga di bidang fisika, mekanika kuantum [2], kimia, dan elektro. Salah satu kegunaan teori grup berhubungan dengan penyelesaian permasalahan enumerasi yang sangat mengandalkan teori grup permutasi dan konsep tindakan grup. Enumerasi dalam hal ini adalah penghitungan atau pencacahan dari suatu pengaturan [3]. Seperti diketahui, dari beberapa permasalahan matematika yang rumit terkait pada penghitungan. Hal ini lebih dikarenakan masalah teknis dan konseptual. Masalah teknis yang sering dihadapi adalah objek yang akan dihitung tidak diatur berurutan. Sedangkan permasalahan konseptual terjadi ketika objek berbeda dapat dipandang sama. Gambarannya seperti dalam pertanyaan sebagai berikut. Berapa banyak segienam berbeda yang dapat diwarnai dengan simpul merah dan kuning? Atau berapa banyak kalung berbeda yang dapat dibentuk dengan mutiara hitam dan putih? Dua objek dikatakan sama atau isomorfis jika objek kedua dapat dibentuk dari hasil rotasi atau refleksi dari objek pertama. Kita paham bahwa ini terkait pada masalah kombinatorik dan terdapat beberapa metode yang dapat menyelesaikan permasalahan tersebut.

Salah satu metodenya adalah Teorema Burnside. Sayangnya, Teorema Burnside dapat mengenumerasi banyaknya objek berbeda tetapi tidak diperoleh bentuk-bentuk objek yang berbeda tersebut. Teroema Polya yang diciptakan oleh George Polya, menggunakan definisi grup permutasi dapat menghasilkan polynomial yang menggambarkan konfigurasi-konfigurasi berbeda dan berapa banyak diantara masing-masing konfigurasi tersebut. Teorema Polya dapat diaplikasikan di berbagai bidang misalnya enumerasi isomer kimia, teori graf, Latin Square, fungsi Boolean, automata, struktur kristal dan bidang musik [4].

Graf merupakan salah satu cabang dari ilmu matematika diskrit. Sebuah graf G adalah pasangan dari himpunan $(V, E)$, dimana $V$ adalah himpunan simpul yang tak kosong, sedangkan $\mathrm{E}$ adalah himpunan sisi yang mungkin merupakan himpunan kosong [5]. Graf sederhana adalah graf yang tidak memilki sisi ganda dan loop. Graf sederhana $G_{1}=\left(V_{1}, E_{1}\right)$ dan $G_{2}=\left(V_{2}, E_{2}\right)$ dikatakan sama atau isomorfis jika terdapat fungsi bijektif $f: V_{1} \rightarrow V_{2}$ dengan sifat $a, b \in V_{1}$ bertetangga jika dan hanya jika $f(a), f(b) \in V_{2}$ bertetangga, untuk setiap $a, b \in V_{1 \text {. [6]. }}$

Masalah enumerasi pada graf yang tidak isomorfis merupakan masalah yang tidak mudah karena harus bisa menemukan satu per satu graf yang tidak isomorfis dan menentukan bentuk dari graf yang tidak isomorfis tersebut. Seperti yang telah disebutkan sebelumnya, salah satu penyelesaian masalah enumerasi pada graf adalah penggunaan Teorema Polya. Teorema Polya I menjelaskan banyaknya graf yang 
tidak isomorfis dan Teorema Polya II menjelaskan bentuk-bentuk graf yang tidak isomorfis tersebut.

Dalam penelitian yang lain, Teorema Polya dapat digunakan dalam menentukan graf sederhana dengan empat simpul yang tidak saling isomorfis [6] dan lima simpul yang tidak saling isomorfis [7]. Oleh sebab itu, penelitian paper ini melanjutkan penentuan banyaknya graf sederhana dengan enam simpul yang tidak saling isomorfis. Pada dasarnya paper ini merupakan penggabungan dari ilmu graf dan teori grup. Teori grup yang digunakan adalah teori grup permutasi dan grup Action.

\section{Indeks Sikel}

Indeks sikel dapat digunakan untuk enumerasi pola yang berhubungan dengan grup, karena dari indeks sikel dapat dihitung orbit dari setiap elemen dari grup permutasi.

Diberikan $G$ adalah grup permutasi dengan order $m$ dari suatu himpunan yang banyak anggotanya $n$ dan $g \in G$ adalah komposisi dari sikel-sikel yang disjoint yang terdiri dari sikel dengan panjang 1 sebanyak $a_{1}$, sikel dengan panjang 2 sebanyak $a_{2}, \ldots$, sikel dengan panjang $n$ sebanyak $a_{n}$ yang memenuhi $1 a_{1}+2 a_{2}+\cdots+$ $n a_{n}=n$, maka tipe permutasi dari $g$ adalah $\left[a_{1}, a_{2}, \ldots, a_{3}\right]$ dan indeks sikel $g$ didefinisikan sebagai : $Z\left(g ; x_{1}, x_{2}, x_{3}, \ldots, x_{n}\right)=x_{1}{ }^{a_{1}} x_{2}{ }^{a_{2}} x_{3}{ }^{a_{3}} \ldots x_{n}{ }^{a_{n}}$.

Serta, indeks sikel dari grup $G$ didefinisikan :

\section{Contoh}

$$
Z\left(G ; x_{1}, x_{2}, x_{3}, \ldots, x_{n}\right)=\frac{1}{m} \sum_{g \in G} Z\left(g ; x_{1}, x_{2}, x_{3}, \ldots, x_{n}\right)
$$

$q=(123) \in S_{3}$, permutasi $q$ memiliki 1 sikel dengan panjang 3, sehingga tipe permutasi $q$ adalah $[0,0,1]$ dan indeks sikel $q$ adalah $x_{1}{ }^{0} x_{2}{ }^{0} x_{3}{ }^{1}=x_{3}$.

\section{Teorema Burnside-Frobenius [8]}

Misal $X$ adalah $G$ - set dengan $G$ dan $X$ berhingga. Jika $k$ adalah banyaknya orbit di $X$ pada $G$, maka:

$\begin{aligned} k & =\frac{1}{|G|} \sum_{g \in G}|F(g)| \\ \text { Dengan } F(g) & =\{z \in X: g(z)=z\}\end{aligned}$

Teorema Burnside-Frobenius dapat digunakan dalam pembuktian Teorema Polya I dan menghitung pola berdasarkan sifat kesimetrian.

Teorema Polya

Teorema Polya I[9]

Diberikan $C=\{f \mid f: X \rightarrow Y\}$ dengan $|X|=n \geq 2$ dan $|Y|=r$. Jika $G$ merupakan grup permutasi yang beraksi pada $X$ dengan indeks siklik $Z\left(G ; x_{1}, x_{2}, x_{3}, \ldots, x_{n}\right)$ maka banyaknya pola di $C$ terhadap $G$ adalah $Z(G ; r, r, r, \ldots, r)$. 


\section{Bukti:}

Jika $g \in G$, maka $f \in F(g) \Leftrightarrow f$ tetap oleh tiap-tiap sikel dari $g$. Dan ika $g$ adalah permutasi bertipe $\left[a_{1}, a_{2}, \ldots, a_{n}\right]$ maka $a_{1}+a_{2}+\cdots+a_{n}$ menyatakan banyaknya sikel disjoint di $g$, sehingga banyaknya permutasi yang tetap oleh $g$ adalah $r^{a_{1}+a_{2}+\cdots+a_{n}}$. Jadi, diperoleh $|F(g)|=r^{a_{1}+a_{2}+\cdots+a_{n}}$ dengan $\left[a_{1}, a_{2}, \ldots, a_{n}\right]$ adalah tipe permutasi $g$. Berdasarkan Teorema Burnside, banyaknya orbit yang berbeda adalah

$$
\begin{aligned}
n & =\frac{1}{|G|} \sum_{g \in G}|F(g)| \\
n & =\frac{1}{|G|} \sum_{g \in G} r^{a_{1}+a_{2}+\cdots+a_{n}} \\
n & =\frac{1}{|G|} \sum_{g \in G} r^{a_{1}} \cdot r^{a_{2}} \ldots r^{a_{n}} \\
n & =\frac{1}{|G|} \sum_{g \in G} z(g ; r, r, \ldots, r) \\
& \quad n=Z(G ; r, r, \ldots, r)
\end{aligned}
$$

\section{Teorema Polya II [10]}

Persediaan pola warna , $\operatorname{PI}\left(G ; w\left(y_{1}\right), w\left(y_{2}\right), w\left(y_{3}\right), \ldots, w\left(y_{r}\right)\right)$ adalah merupakan indeks siklik dari $Z\left(G ; x_{1}, x_{2}, x_{3}, \ldots, x_{n}\right)$ pada $x_{i}=\left(w\left(y_{1}\right)\right)^{i}+\left(w\left(y_{2}\right)\right)^{i}+$ $\left(w\left(y_{3}\right)\right)^{i}+\cdots+\left(w\left(y_{r}\right)\right)^{i}$ dengan $i=1,2,3, \ldots, n$

\section{Graf Isomorfis}

Graf $G$ didefinisikan sebagai pasangan himpunan $(V, E)$ dengan $V$ adalah himpunan dari simpul-simpul tidak kosong dan $E$ adalah himpunan dari sisi-sisi yang menghubungkan dua simpul dan mungkin kosong.

Dua buah graf $G_{1}$ dan $G_{2}$ dengan $G_{1}=\left(V_{1}, E_{1}\right)$ dan $G_{2}=\left(V_{2}, E_{2}\right)$ dikatakan isomorfis jika terdapat fungsi bijektif $f: V_{1} \rightarrow V_{2}$ dengan sifat $a, b \in V_{1}$ bertetangga jika dan hanya jika $f(a), f(b) \in V_{2}$ bertetangga , untuk setiap $a, b \in V_{1}$.

\section{Contoh}

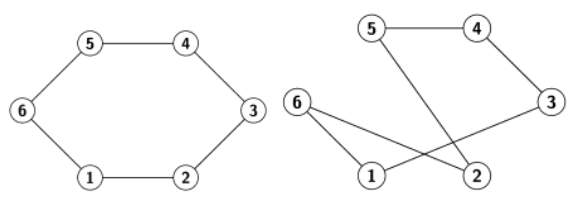

Gambar 3.1: Dua Graf yang Saling Isomorfis

dua graf pada Gambar 2.1 adalah dua graf yang saling isomorfis dengan fungsi bijektif

$f(1)=5, f(2)=4, f(3)=3, f(4)=1, f(5)=6 \operatorname{dan} f(6)=2$. 


\section{Enumerasi Graf Sederhana Enam Simpul dengan Menggunakan Teorema Polya}

Diberikan himpunan $X=\{1,2,3,4,5,6\}$ yang merupakan himpunan simpul dari suatu graf dengan $n=6$. Apabila $n$ simpul pada graf dikenai permutasi maka pasangan simpul tak terurut dari graf tersebut juga mengalami permutasi. Pasangan simpul tak terurut dapat dipandang sebagai suatu sisi. Jika himpunan permutasi pada simpul-simpul suatu graf membentuk suatu graf simetri $\left(S_{n}\right)$, seluruh bentuk grup $S_{n}$ adalah $n !=6 !=720$.

Selanjutnya dari elemen-elemen permutasi tersebut akan diperoleh tipe permutasi dan indeks sikel permutasi. Pola tipe-tipe rantai yang diperoleh sebagai berikut:

1. Bentuk $[6,0,0,0,0,0]$ ada 1 dengan indeks sikelnya $x_{1}^{6}$

2. Bentuk $[4,1,0,0,0,0]$ ada 15 dengan indeks sikelnya $x_{1}^{4} x_{2}$

3. Bentuk $[3,0,1,0,0,0]$ ada 40 dengan indeks sikelnya $x_{1}^{3} x_{3}$

4. Bentuk $[2,2,0,0,0,0]$ ada 45 dengan indeks sikelnya $x_{1}^{2} x_{2}^{2}$

5. Bentuk $[2,0,0,1,0,0]$ ada 90 dengan indeks sikelnya $x_{1}^{2} x_{4}$

6. Bentuk $[1,1,1,0,0,0]$ ada 120 dengan indeks sikelnya $x_{1} x_{2} x_{3}$

7. Bentuk $[1,0,0,0,1,0]$ ada 144 dengan indeks sikelnya $x_{1} x_{5}$

8. Bentuk $[0,1,0,1,0,0]$ ada 90 dengan indeks sikelnya $x_{2} x_{4}$

9. Bentuk $[0,0,2,0,0,0]$ ada 40 dengan indeks sikelnya $x_{3}^{2}$

10. Bentuk $[0,3,0,0,0,0]$ ada 15 dengan indeks sikelnya $x_{2}^{3}$

11. Bentuk $[0,0,0,0,0,1]$ ada 120 dengan indeks sikelnya $x_{6}$

Jika himpunan permutasi pada simpul-simpul suatu graf membentuk suatu grup simetri $\left(S_{n}\right)$, maka permutasi dari pasangan terurut simpul tersebut juga membentuk suatu grup permutasi $\left(R_{n}\right)$. Sehingga akan dibentuk indeks sikel $R_{n}$ (permutasi sisi pada graf) dengan membangkitkan indeks sikel pada $S_{6}$ yang sudah diperoleh. Sebagai contoh,

$\mathrm{B}=(12)$ dengan bentuk $[4,1,0,0,0,0]$ dengan indeks sikel : $x_{1}^{4} x_{2}$

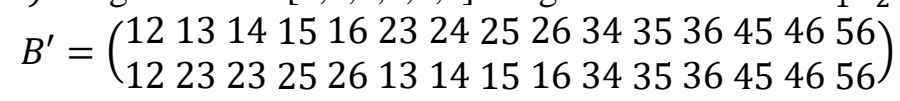

Karena terdapat lima belas sisi pada graf awal yang kemudian menjadi simpul pada graf yang baru, maka pada permutasi $B^{\prime}$ terdapat tujuh sikel dengan panjang satu, dan empat sikel dengan panjang dua.

Sehingga dapat dikatakan, $B^{\prime}$ mempunyai indeks sikel $x_{1}^{7} x_{2}^{4}$. Ilustrasinya sebagai berikut

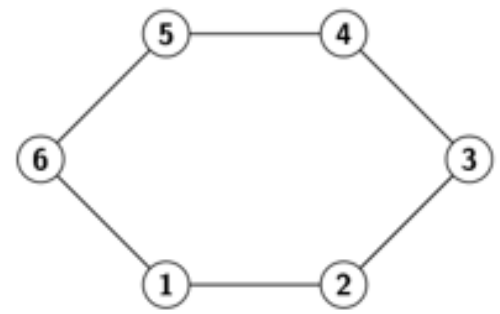

(1 2 )

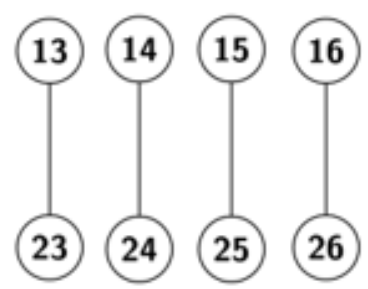

$(1323)(1424)(1525)(1626)$

Gambar 4.2: Ilustrasi Perubahan Indeks Sikel

Keseluruhan perubahan indeks sikel $S_{6}$ menjadi indeks sikel $R_{6}$ dinyatakan dalam Tabel 4.2. 
Tabel 4.2 Perubahan Indeks Sikel

\begin{tabular}{|l|c|c|}
\hline No. & $S_{n}$ & $R_{n}$ \\
\hline 1 & $x_{1}^{6}$ & $x_{1}^{15}$ \\
\hline 2 & $x_{1}^{4} x_{2}$ & $x_{1}^{7} x_{2}^{4}$ \\
\hline 3 & $x_{1}^{3} x_{3}$ & $x_{1}^{3} x_{3}^{4}$ \\
\hline 4 & $x_{1}^{2} x_{2}^{2}$ & $x_{1}^{3} x_{2}^{6}$ \\
\hline 5 & $x_{1}^{2} x_{4}$ & $x_{1} x_{2} x_{4}^{3}$ \\
\hline 6 & $x_{1} x_{2} x_{3}$ & $x_{1} x_{2} x_{3}^{2} x_{6}$ \\
\hline 7 & $x_{1} x_{5}$ & $x_{5}^{3}$ \\
\hline 8 & $x_{2} x_{4}$ & $x_{1} x_{2} x_{4}^{3}$ \\
\hline 9 & $x_{3}^{2}$ & $x_{3}^{5}$ \\
\hline 10 & $x_{2}^{3}$ & $x_{1}^{3} x_{2}^{6}$ \\
\hline 11 & $x_{6}$ & $x_{3} x_{6}^{2}$ \\
\hline
\end{tabular}

Sehingga dengan menggunakan Teorema Polya I diperoleh :

$$
\begin{aligned}
& Z\left(R_{6} ; x_{1}, x_{2}, x_{3}, x_{4}, x_{5}, x_{6}\right) \\
& \begin{array}{c}
=\frac{1}{720}\left[x_{1}^{15}+15 x_{1}^{7} x_{2}^{4}+40 x_{1}^{3} x_{3}^{4}+45 x_{1}^{3} x_{2}^{6}\right. \\
+90 x_{1} x_{2} x_{4}^{3}+120 x_{1} x_{2} x_{3}^{2} x_{6}+144 x_{5}^{3}+ \\
90 x_{1} x_{2} x_{4}^{3}+40 x_{3}^{5}+15 x_{1}^{3} x_{2}^{6}+120 x_{3} x_{6}^{2}
\end{array}
\end{aligned}
$$

Diberikan $f: X \rightarrow Y$ dengan $|Y|=r$. Pada graf sederhana hanya terdapat dua keadaan pada himpunan Y, yaitu ada himpunan sisi pada himpunan simpul dan tidak ada sisi pada himpunan simpul, sehingga $r=2$ maka menyebabkan $x_{1}=x_{2}=$ $x_{3}=x_{4}=x_{5}=x_{6}=2$, dengan memasukkan nilai tersebut pada Persamaan (2) diperoleh :

$Z\left(R_{6} ; 2,2,2,2,2,2\right)$

$$
\begin{aligned}
& =\frac{1}{720}\left[2^{15}+15 \cdot 2^{7} \cdot 2^{4}+40 \cdot 2^{3} \cdot 2^{4}+45 \cdot 2^{3} \cdot 2^{6}+90 \cdot 2 \cdot 2 \cdot 2^{3}\right. \\
& +120 \cdot 2 \cdot 2 \cdot 2^{2} \cdot 2+144 \cdot 2^{3}+90 \cdot 2 \cdot 2 \cdot 2^{3}+40 \cdot 2^{5}+15 \cdot 2^{3} \cdot 2^{6} \\
& \left.+120 \cdot 2 \cdot 2^{2}\right]
\end{aligned}
$$

$Z\left(R_{6} ; 2,2,2,2,2,2\right)$

$$
\begin{aligned}
= & \frac{1}{720}[32768+30720+5120+23040+2880+3840 \\
+ & 1152+2880+1280+7680+960] \\
& Z\left(R_{6} ; 2,2,2,2,2,2\right)=\frac{1}{720}[112320]=156
\end{aligned}
$$

Jadi, untuk graf sederhana dengan enam simpul, maka akan terdapat 156 graf yang tidak saling isomorfis.

Ambil dua pola pada himpunan $\mathrm{Y}$, misalkan $T=\operatorname{tidak}$ mempunyai sisi dan $A=$ mempunyai sisi, kemudian substitusikan

$x_{1}=T+A, x_{2}=T^{2}+A^{2}, x_{3}=T^{3}+A^{3}, x_{4}=T^{4}+A^{4}, x_{5}=T^{5}+A^{5} \mathrm{dan} x_{6}=$ $T^{6}+A^{6}$ pada Persamaan (2), sehingga diperoleh : 


$$
\begin{aligned}
Z\left(R_{6} ; x_{1}, x_{2}, x_{3},\right. & \left.x_{4}, x_{5}, x_{6}\right) \\
& =\frac{1}{720}\left[(T+A)^{15}+15 \cdot(T+A)^{7} \cdot\left(T^{2}+A^{2}\right)^{4}\right. \\
& +40 \cdot(T+A)^{3} \cdot\left(T^{3}+A^{3}\right)^{4}+45 \cdot(T+A)^{3} \cdot\left(T^{2}+A^{2}\right)^{6} \\
& +90 \cdot(T+A) \cdot\left(T^{2}+A^{2}\right) \cdot\left(T^{4}+A^{4}\right)^{3} \\
& +120 \cdot(T+A) \cdot\left(T^{2}+A^{2}\right) \cdot\left(T^{3}+A^{3}\right)^{2} \cdot\left(T^{6}+A^{6}\right) \\
& +144 \cdot\left(T^{5}+A^{5}\right)^{3}+90 \cdot(T+A) \cdot\left(T^{2}+A^{2}\right) \cdot\left(T^{4}+A^{4}\right)^{3} \\
& +40 \cdot\left(T^{3}+A^{3}\right)^{5}+15 \cdot(T+A)^{3} \cdot\left(T^{2}+A^{2}\right)^{6}+120 \cdot\left(T^{3}\right. \\
& \left.\left.+A^{3}\right) \cdot\left(T^{6}+A^{6}\right)^{2}\right]
\end{aligned}
$$

Dilakukan perkalian pada setiap suku di ruas kanan kemudian disederhanakan sehingga diperoleh :

$$
\begin{aligned}
& Z\left(R_{6} ; x_{1}, x_{2}, x_{3}, x_{4}, x_{5}, x_{6}\right)=T^{15}+T^{14} A+2 T^{13} A^{2}+5 T^{12} A^{3}+9 T^{11} A^{4}+ \\
& 15 T^{10} A^{5}+21 T^{9} A^{6}+24 T^{8} A^{7}+24 T^{7} A^{8}+21 T^{6} A^{9}+15 T^{5} A^{10}+9 T^{4} A^{11}+ \\
& 5 T^{3} A^{12}+2 T^{2} A^{13}+T A^{14}+A^{15}
\end{aligned}
$$

Berdasarkan persamaan (3) diperoleh bentuk-bentuk graf yang tidak isomorfis dengan bantuan software Graph Algorithm Programing menggunakan konsep graf kompelemen:

\begin{tabular}{|l|l|}
\hline Satu graf tanpa sisi & \\
\hline $\begin{array}{l}\text { Satu graf dengan satu } \\
\text { sisi }\end{array}$ 年 \\
sisi
\end{tabular}




\begin{tabular}{|l|}
\hline $\begin{array}{l}\text { Dua puluh empat graf } \\
\text { dengan delapan sisi }\end{array}$ \\
\hline $\begin{array}{l}\text { Dua puluh satu graf } \\
\text { dengan Sembilan sisi }\end{array}$ \\
\hline $\begin{array}{l}\text { Lima belas graf dengan } \\
\text { sepuluh sisi }\end{array}$ \\
\hline $\begin{array}{l}\text { Sembilan graf dengan } \\
\text { sebelas sisi }\end{array}$ \\
\hline $\begin{array}{l}\text { Lima graf dengan dua } \\
\text { belas sisi }\end{array}$ \\
\hline $\begin{array}{l}\text { Dua graf dengan tiga } \\
\text { belas sisi }\end{array}$ \\
\hline $\begin{array}{l}\text { Satu graf dengan empat } \\
\text { belas sisi }\end{array}$ \\
\hline $\begin{array}{l}\text { Satu graf dengan lima } \\
\text { belas sisi }\end{array}$ \\
\hline
\end{tabular}

\section{Daftar Pustaka}

[1] Kleiner, I. (1986) The Evolution of Group Theory: A Brief Survey. Mathematics Magazine, Volume 59, No. 4, p.195-215.

[2] McWilliams, B., Donahue J. (2006) Applications of Permutation Groups. Abstract Algebra Lecture Note.

[3] Mahmudah, W. (2006). Kajian Indeks Sikel Polinomial Grup dan Aplikasi TeoremaPolya Pada Molekul Tetrahedron, Tugas Akhir Jurusan Matematika Institut Teknologi Sepuluh Nopember Surabaya.

[4] Cattani M. (2007), Quantum Statitics: The Industinguishability Principle and The Permutation Group Theory, RevistaBrasileira de Ensino de Fisica, Volume 29, No.3, p.405-414.

[5] Fripertinger H. 1992. Enumeration in Musical Theory. Seminaire Lotharingien de Com-binatoire, 476/S-26:2942. ISSN 0755-3390.

[6] Gunawan R., S. (2003) Aplikasi Teorema Polya Pada Enumerasi Graf Sederhana. Jurnal Matematika dan Komputasi. 1(8):1 - 10.

[7] Rosalianti T. V., Suhery C., Kusumasti, N. (2013) Penggunaan TeoremaPolya Dalam Menentukan Banyaknya Graf Sederhana yang Tidak Saling Isomorfis, Buletin Ilmiah Mat.Stat. dan Terapannya. Volume 02, No.1 Hal 39-44.

[8] Mulholland Jamie,.Permutation Puzzles: A Mathematical Perspective. 16 Februari 2015. http://people.math.sfu.ca/ jtmulhol/math302/notes/22-OrbitStabilizer.pdf.

[9] Brualdi, Richard A.(2009) Introductory Combinatoric. New York: Pearson Education Inc. 